\title{
DESAFIOS DA INTEGRAÇÃO CURRICULAR: A PRÁTICA INTERDISCIPLINAR NOS ESPAÇOS DOS SEMINÁRIOS INTEGRADOS
}

Tábata Valesca Corrêa ${ }^{(*)}$ Luís Armando Gandin ${ }^{(* *)}$

\section{INTRODUÇÃO}

Este artigo apresenta os resultados de um estudo realizado em uma escola da rede pública estadual do Rio Grande do Sul, no contexto do Ensino Médio Politécnico, em que analisamos as práticas curriculares de professores e professoras, tendo em vista o espaço dos Seminários Integrados, com foco na interdisciplinaridade. O objetivo deste estudo é investigar a prática interdisciplinar a partir da proposta de integração curricular por meio dos Seminários Integrados.

Os referenciais teóricos que sustentam este trabalho foram criados na intersecção dos campos das Teorias Educacionais Críticas e da Sociologia da Educação, cujas ferramentas teóricometodológicas possibilitam uma análise relacional do currículo em interface com as políticas educacionais e demais esferas que incidem sobre esse campo. Nessa perspectiva, o conceito de currículo, a partir das teorias de Apple (2006), Sacristán (2000), Santomé (1998) e Bernstein (1996), é estruturante deste estudo. O currículo é também o campo estudado nesse trabalho de pesquisa. Os caminhos metodológicos foram percorridos através de três processos de coleta de dados: observações das atividades desenvolvidas nos Seminários Integrados, questionários com professores e professoras que atuam em turmas do ensino médio na escola estudada e entrevistas com professoras de Seminários Integrados e da equipe de supervisão pedagógica desta escola. A partir da análise dos dados levantados, nosso objetivo é examinar os desafios, limites e possibilidades da integração curricular, instituída na rede escolar pública estadual do Rio Grande do Sul por meio do Ensino Médio Politécnico, tendo como foco a prática interdisciplinar.

Iniciaremos apresentando o contexto deste estudo, com finalidade de situar o leitor e caracterizar elementos importantes da política do Ensino Médio Politécnico. Em seguida,

\footnotetext{
${ }^{(*)}$ Mestra em Educação pela Universidade Federal do Rio Grande do Sul. Doutoranda em Educação do Programa de PósGraduação em Educação da Universidade Federal do Rio Grande do Sul.

${ }^{(* *)}$ Doutor em Educação pela University of Wisconsin-Madison, Estados Unidos e Professor Titular da Faculdade de Educação e do Programa de Pós-Graduação em Educação da Universidade Federal do Rio Grande do Sul. É Bolsista de Produtividade em Pesquisa do $\mathrm{CNPq}$
} 
apresentaremos as concepções teóricas a partir das quais compreendemos o campo do currículo e cujas lentes orientaram o desenvolvimento desta pesquisa. Por fim, discutiremos os desafios da integração curricular a partir das experiências analisadas no contexto escolar, com base nos dados da pesquisa, tendo como foco o princípio da interdisciplinaridade e os espaços dos Seminários Integrados.

\section{CONTEXTO DO ENSINO MÉDIO POLITÉCNICO}

O contexto no qual esse estudo foi realizado é o do processo de reestruturação curricular do ensino médio nas escolas da rede pública estadual do Rio Grande do Sul, cuja proposta foi instituída pela equipe da Secretaria Estadual de Educação do Rio Grande do Sul (SEDUC-RS), durante a gestão 2011-2014. Esse contexto é parte de uma conjuntura política de governo do Partido dos Trabalhadores (PT) e foi marcado por um conjunto de ações e de políticas públicas de apoio e fortalecimento de propostas curriculares inovadoras voltadas para o ensino médio, articuladas em âmbito nacional.

Como parte das ações de fortalecimento do ensino médio, o governo do estado do RS construiu uma Proposta Pedagógica para o Ensino Médio Politécnico e Educação Profissional Integrada ao Ensino Médio - a qual nos referimos neste estudo como política do Ensino Médio Politécnico $^{1}$ - na tentativa de consolidar as Diretrizes Curriculares Nacionais para o Ensino Médio aprovadas no ano de 2012, (DCNEM/2012) $)^{2}$ Essa proposta previa a reestruturação do currículo escolar, aumentando a carga horária dessa etapa da educação, bem como sua redistribuição na matriz curricular, além de instituir os Seminários Integrados como parte diversificada do currículo e estabelecer princípios orientadores das práticas de professores e professoras, prevendo que a integração curricular por meio desses princípios no processo formativo.

\footnotetext{
${ }^{1}$ O Ensino Médio Politécnico é definidor da modalidade de nível médio da Educação Básica voltada à formação geral do educando, portanto não se confunde com ensino técnico. Embora a proposta contemple também a modalidade de educação profissional integrada ao ensino médio, não abordamos esta modalidade neste estudo, tendo em vista que a pesquisa tem como foco de investigação as práticas curriculares atuadas no ensino médio regular.

${ }^{2}$ As DCNEM/2012 reorganizam as áreas do conhecimento que compõem o currículo do ensino médio, passando a definir a Matemática como área de conhecimento independente das Ciências da Natureza. Assim, ficam estabelecidas quatro áreas, quais sejam: 1) Linguagens; 2) Matemática; 3) Ciências da Natureza; 4) Ciências Humanas. Anteriormente, a organização definida pelas DCNEM/1998 estabelecia três áreas do conhecimento, a saber: 1) Linguagens, Códigos e suas Tecnologias; 2) Ciências da Natureza, Matemática e suas Tecnologias; 3) Ciências Humanas e suas Tecnologias.
} 
Em relação às modificações na carga horária, a proposta previa que o curso do ensino médio fosse desenvolvido ao longo de três anos, totalizando 3000 horas-aula em vez das 2400 horas-aula previstas anteriormente. Essa carga horária total foi dividida em 1000 horas-aula para cada ano do curso, sendo no primeiro ano $75 \%$ de formação geral e $25 \%$ de parte diversificada; no segundo ano, $50 \%$ para cada formação; no terceiro ano as proporções se invertem e a parte diversificada passa a compor $75 \%$ do currículo, sendo $25 \%$ de formação geral (RIO GRANDE DO SUL, 2011). Essas duas dimensões do currículo proposto - formação geral e parte diversificada - não são excludentes no que se refere aos seus objetivos formativos, mas pressupõem diferentes ênfases pedagógicas, metodológicas e avaliativas (Ibidem). Em relação a essa composição curricular em duas dimensões,

Entende-se por formação geral (núcleo comum), um trabalho interdisciplinar com as áreas de conhecimento com o objetivo de articular o conhecimento universal sistematizado e contextualizado com as novas tecnologias, com vistas à apropriação e integração com o mundo do trabalho. Entende-se por parte diversificada (humana - tecnológica politécnica), a articulação das áreas do conhecimento com objetivo de experiências e vivências, com o mundo do trabalho, a qual apresente opções e possibilidades para posterior formação profissional nos diversos setores da economia e do mundo do trabalho. (Ibidem, 2011, p. 23, grifos nossos).

No sentido de articular a formação geral à parte diversificada e assim promover a integração por meio das áreas de conhecimento, bem como potencializar a consolidação dos princípios orientadores das práticas dos professores e professoras nesse processo, os Seminários Integrados foram instituídos como componente curricular da parte diversificada. Salientamos que as mudanças estabelecidas por essa proposta buscavam promover a integração curricular por meio de princípios orientadores alicerçados na legislação nacional.

Esses princípios estabelecidos como estruturantes das práticas curriculares no âmbito do Ensino Médio Politécnico referem-se à relação parte/totalidade; reconhecimento de saberes; relação teoria prática; interdisciplinaridade; avaliação emancipatória; e pesquisa como princípio pedagógico.

O documento-base do Ensino Médio Politécnico, ao apresentar esses princípios orientadores, expressa que a "interdisciplinaridade se apresenta como um meio, eficaz e eficiente, de articulação do estudo da realidade e produção de conhecimento com vistas à transformação" (RIO GRANDE DO SUL, 2011, p. 19). Ainda em relação ao princípio da interdisciplinaridade, o documento expõe que "o trabalho interdisciplinar, como estratégia metodológica, viabiliza o estudo 
de temáticas transversalizadas, o qual alia a teoria e a prática, tendo sua concretude por meio de ações pedagógicas integradoras" (Ibidem, p. 18). Além disso, o documento coloca que "o desafio de compreender fatos e realidades amplas e complexas, a partir da escolha de conteúdos curriculares, demanda uma relação constante entre a parte e a totalidade" (Ibidem, p. 17). A partir desse documento, entendemos que a proposta sinaliza para a articulação entre os princípios orientadores em vista de um objetivo comum, que podemos conceber, em última instância, como a integração curricular. Nesse sentido, considerando a perspectiva do Ensino Médio Politécnico, a partir da qual esses princípios estão inter-relacionados, é importante salientar que esse artigo foca a prática interdisciplinar situada em relação aos demais princípios.

Em relação aos Seminários Integrados, este componente curricular constitui-se em "espaços planejados, integrados por professores e alunos [...]. Organizam o planejamento, a execução e a avaliação de todo o projeto político pedagógico, de forma coletiva, incentivando a cooperação, a solidariedade e o protagonismo do jovem adulto" (RIO GRANDE DO SUL, 2011, p. 23). A política do Ensino Médio Politécnico preconiza, ainda, que os Seminários Integrados promovam a integração curricular no âmbito das relações pedagógicas, dos conhecimentos disciplinares, da avaliação por área do conhecimento e dos princípios que orientam essa política educacional. Nesse sentido, os Seminários Integrados compõem espaços-tempos de elaboração e desenvolvimento de projetos interdisciplinares de pesquisa escolar, cujo objetivo é integrar as áreas do conhecimento.

É importante antecipar que, no contexto estudado, os princípios orientadores estabelecidos pela proposta foram identificados como um espectro de presenças ausentes nas práticas dos professores e professoras da escola. Essa análise reforça a hipótese deste estudo de que os princípios orientadores estabelecidos pelo Ensino Médio Politécnico não costumam fazer parte da tradição cultural e institucional de práticas de grande parte das escolas. Contudo, ainda que a maioria desses princípios, em geral, não tenham sido concretizados nas práticas curriculares, foram elementos importantes de tensionamento sobre o currículo da escola estudada e sobre a tradição cultural e institucional de práticas da mesma, como mostraremos com base nos dados obtidos na pesquisa. Neste estudo, a prática interdisciplinar ganhou destaque, pois a inserção dos Seminários Integrados no currículo desta escola promoveu tensionamentos no sentido da integração curricular, sobretudo por meio do princípio da interdisciplinaridade.

Para compreender os desdobramentos das experiências documentadas neste estudo, voltadas para a integração curricular por meio dos Seminários Integrados e tendo em vista a prática interdisciplinar, consideramos importante apresentar nosso entendimento sobre o campo do currículo. Assim sendo, apresentamos uma construção teórica desse campo, tendo em vista a 
discussão sobre as possibilidades de construção de um currículo integrado em diálogo com uma perspectiva fragmentária de currículo, cuja estrutura tem organizado nosso sistema curricular e escolar de modo geral.

\section{O CURRÍCULO EM PERSPECTIVA}

As teorias do currículo que sustentam as análises deste estudo baseiam-se na perspectiva crítica, cujos autores situam o conhecimento sempre em relação com as relações de poder, buscando evidenciar que o currículo corresponde a um campo dinâmico de disputas e embates entre os diversos interesses relativos às esferas mais amplas da sociedade. Dessa maneira, o currículo pode ser entendido como um campo que envolve "a maior parte dos conflitos concretos em torno da organização do sistema escolar” (SILVA, 1992, p. 76). Nesse sentido, Sacristán (2000) argumenta que

Os currículos são a expressão do equilíbrio de interesses e forças que gravitam sobre o sistema educativo num dado momento, enquanto através deles se realizam os fins da educação no ensino escolarizado. Por isso, querer reduzir os problemas relevantes do ensino à problemática técnica de instrumentalizar o currículo supõe uma redução que desconsidera os conflitos de interesses que estão presentes no mesmo. (SACRISTÁN, 2000, p. 17).

A concepção hegemônica de currículo tecnicista permanece em evidência no cenário educacional brasileiro, legitimando concepções e práticas baseadas na lógica da eficiência, do consenso e da neutralidade, características que persistem, como já constatava Silva (1990) há mais de duas décadas. Os problemas relativos ao currículo, portanto, continuam sendo em grande medida pensados e enfrentados sob a perspectiva da racionalidade técnica, a partir da definição de conteúdos e métodos objetivos, de estratégias mais eficazes e eficientes de ensino, bem como de instrumentos mais rigorosos e precisos de avaliação. Essa perspectiva faz com que as relações políticas e o debate político que perpassam os campos da educação e do currículo não sejam considerados e qualquer discussão sobre essas relações e debates sejam substituídas pelo discurso da eficiência e dos resultados. Além disso, essa perspectiva pauta toda uma tradição de seleção e organização curricular que oculta as disputas de poder no campo do conhecimento.

Normalmente, a construção do conhecimento disciplinar realiza-se mediante uma seleção de dados significativos e rejeição dos não pertinentes, porém tal atividade seletiva está 
controlada e dirigida por modelos ou "paradigmas" que organizam o pensamento e a visão da ciência e da realidade. (SANTOMÉ, 1998, p. 60).

Nesse sentido, Apple (2000) argumenta que "O currículo nunca é simplesmente uma montagem neutra de conhecimentos [...]. Ele é produzido pelos conflitos, tensões e compromissos culturais, políticos e econômicos que organizam e desorganizam um povo" (APPLE, 2000, p. 53). Sobre isso, com base na teoria de Bernstein, reitera-se que "Não existe nada de intrínseco no modo como um dado currículo é estruturado, pois que, independentemente da lógica intrínseca às várias formas de conhecimento, as formas da sua transmissão são factos sociais" (DOMINGOS et al., 1986, p. 151).

No sistema educacional brasileiro, "sem dúvida, a forma mais clássica de organização do conteúdo, ainda predominante atualmente ${ }^{3}$, é o modelo linear disciplinar, ou conjunto de disciplinas justapostas, na maioria das vezes de uma forma bastante arbitrária” (SANTOMÉ, 1998, p. 103, grifos no original). Sobre essa organização dos conhecimentos escolares, vale lembrar que, historicamente,

as necessidades da industrialização promovida a partir de modelos econômicos capitalistas, as revoluções industriais e os processos de transformação das sociedades agrárias da época abriram [sic] o caminho para maiores parcelas de disciplinaridade do conhecimento. As indústrias necessitavam urgentemente de especialistas para enfrentar os problemas e objetivos específicos de seus processos de produção e comercialização. [...] Naturalmente, uma sociedade que está sendo construída com base no trabalho fragmentado nos âmbitos da produção industrial e comercial amplia esta filosofia da divisão para o mundo da ciência. (Ibidem, p. 47-48, grifo no original).

Entretanto, Santomé (1998) também alerta para as fortes contradições que as transformações sociais, culturais, econômicas e produtivas acarretam para a esfera das ciências e, portanto, do conhecimento. Nesse sentido, diferentes demandas ocasionadas no bojo dessas transformações implicam em diferentes modos de organização curricular. "O currículo pode ser organizado não só em torno de disciplinas, [...], mas de núcleos que ultrapassam os limites das disciplinas, centrados em temas, problemas, tópicos, instituições, períodos históricos, espaços geográficos, grupos humanos, idéias, etc.” (SANTOMÉ, 1998, p. 25). Dessa forma, o autor evidencia alguns espaços

${ }^{3}$ Constatação realizada por Santomé na década de 1990, mas que representa o cenário educacional atual no Brasil. 
para superação da disciplinaridade curricular linear e fragmentada, argumentando, ainda, que a necessidade da integração e da interdisciplinaridade é urgente, pois

\begin{abstract}
O mundo em que vivemos já é um mundo global, no qual tudo está relacionado, tanto nacional quanto internacionalmente; um mundo onde as dimensões financeiras, culturais, políticas, ambientais, científicas, etc., são interdependentes, e onde nenhum de tais aspectos pode ser compreendido de maneira adequada à margem dos demais. Qualquer tomada de decisão em algum desses setores deve implicar uma reflexão sobre as repercussões e os efeitos colaterais que cada um provocará nos âmbitos restantes. (SANTOMÉ, 1998, p. 27).
\end{abstract}

Uma discussão pormenorizada dessas questões envolvendo a estruturação curricular por disciplinas (justapostas ou integradas) foi desenvolvida por Bernstein, incorporada neste estudo principalmente pelas leituras de Domingos et al. (1986), tendo em vista que essa discussão mostrou-se fundamental para uma análise sobre as práticas curriculares de professores e professoras na perspectiva da interdisciplinaridade no contexto do Ensino Médio Politécnico.

A partir dos estudos da teoria desenvolvida por Bernstein, as autoras explicam que existem forças que estabelecem fronteiras entre os conteúdos curriculares, forjando entre os mesmos "uma relação aberta, com fronteiras esbatidas, ou uma relação fechada, com fronteiras bem definidas, e, portanto, perfeitamente isolados uns dos outros" (DOMINGOS et al., 1986, p. 151, grifos no original). Essas relações fronteiriças traduzem-se em estruturas curriculares que podem ser de currículo de coleção (justaposição das disciplinas que o compõem) ou de integração. Ainda, essas relações são balizadas por forças, mais ou menos pujantes, sobre as fronteiras que definem essas estruturas, estabelecendo limites de classificação e de enquadramento dos conhecimentos e das disciplinas no interior de uma estrutura curricular. Bernstein faz uso dos conceitos de classificação e enquadramento com base nos estudos de Marx e Durkheim, "que haviam mostrado que a estrutura das classificações e dos enquadramentos da sociedade revela a distribuição do poder e os princípios de controle social” (DOMINGOS et al., 1986, p. 153). Em relação especialmente ao conjunto de elementos curriculares, segundo Bernstein (1996), “o 'quê' refere-se às categorias, conteúdos e relações a serem transmitidas, isto é, à sua classificação, e o 'como' se refere ao modo de sua transmissão, essencialmente, ao enquadramento" (BERNSTEIN, 1996, p. 277, grifos no original).

No quadro teórico adotado nesta pesquisa, os conceitos de classificação e enquadramento desenvolvidos por Bernstein ajudam a pensar em alguns elementos da prática curricular por meio dos quais uma determinada estrutura de currículo se consolida. Esses elementos são fundamentais para uma análise da integração curricular por meio do princípio da interdisciplinaridade. 
Destacamos, portanto, as definições dos conceitos de classificação e enquadramento, concebidos por Bernstein, de modo elucidativo nas palavras de Domingos et al. (1986).

A classificação não se refere aqui ao que é classificado, mas às relações entre os conteúdos, isto é, à natureza da diferenciação entre conteúdos. Quando a classificação é forte, os conteúdos estão bem isolados uns dos outros por fronteiras nítidas; quando a classificação é fraca, o isolamento entre os conteúdos é reduzido porque as fronteiras são esbatidas. A classificação refere-se assim ao grau de manutenção das fronteiras entre os conteúdos, correspondendo a força da fronteira ao aspecto distintivo crítico da divisão do conhecimento educacional. O enquadramento refere-se à forma do contexto no qual é feita a transmissão-aquisição do conhecimento, isto é, à força da fronteira entre o que pode e o que não pode ser transmitido numa relação pedagógica. Quando o enquadramento é forte, existe uma fronteira nítida entre o que pode e o que não pode ser transmitido; quando o enquadramento é fraco essa fronteira é esbatida. [...] $O$ enquadramento refere-se assim ao controlo que o professor e o aluno possuem sobre a selecção, organização, ritmagem e organização do tempo do conhecimento a ser transmitido-adquirido na relação pedagógica. (DOMINGOS et al., 1986, p. 154, grifos no original).

Essas relações teorizadas por Bernstein no campo curricular, tanto de ordem simbólica quanto política, levaram-no a conceber o currículo como uma espécie de estrutura de transmissão de conhecimentos que, como vimos, pode ser de tipo coleção ou integração (DOMINGOS et al., 1986, p. 149). Nessa perspectiva, a estruturação do currículo de forma disciplinar linear, comumente presente na organização curricular da maioria das escolas, acaba configurando-se, em geral, como um currículo de tipo coleção, conforme a terminologia de Bernstein (SANTOMÉ, 1998). Tentativas de superação dessa forma de estrutura curricular, buscando alcançar a integração, levam-nos ao debate sobre a interdisciplinaridade, especialmente sobre os desafios e limites de sua concretização, tendo em vista a complexidade dos aspectos teórico-conceituais que esse termo carrega e os obstáculos encontrados na prática.

A interdisciplinaridade é um objetivo nunca completamente alcançado e por isso deve ser
permanentemente buscado. Não é apenas uma proposta teórica, mas sobretudo uma prática.
[...] é realizável na prática; na medida em que são feitas experiências reais de trabalho em
equipe, exercitam-se suas possibilidades, problemas, limitações. (SANTOMÉ, 1998, p. 66).

Com esse posicionamento de que as possibilidades da interdisciplinaridade, bem como seus limites, revelam-se na prática, buscamos problematizar neste artigo a integração curricular guiada pelos desafios, limites e possibilidades da prática interdisciplinar. Sob essa perspectiva, 
mostraremos como as tentativas de integração curricular manifestaram-se nos espaços dos Seminários Integrados a partir das práticas de professoras e professores no contexto da escola estudada.

\section{INTEGRAÇÃO CURRICULAR POR MEIO DA PRÁTICA INTERDISCIPLINAR NO ÂMBITO DOS SEMINÁRIOS INTEGRADOS}

Em confluência com as DCNEM/2012, a política do Ensino Médio Politécnico estabeleceu que as escolas realizassem a organização curricular por área do conhecimento. Nessa perspectiva, a inserção dos Seminários Integrados como componente curricular buscava ultrapassar a mera justaposição das disciplinas em cada uma das áreas do conhecimento definidas nas diretrizes, na tentativa de tensionar rupturas com um currículo disciplinar, ou "de coleção" como na terminologia de Bernstein (1996).

O Ensino Médio Politécnico, nesse sentido, ao reforçar a proposta de organização do currículo por áreas do conhecimento e instituindo os Seminários Integrados, potencializou, nas escolas da rede estadual do Rio Grande do Sul, a possibilidade de um currículo integrado. Para tanto, essa política preconizou que a integração dos conhecimentos escolares fosse concretizada na prática curricular, reiterando o entendimento desse campo como práxis, como uma prática na qual são estabelecidos diálogos e relações entre os conhecimentos e os sujeitos que o vivenciam (tal como no entendimento de SACRISTÁN, 2000). A proposta definia, portanto, que nos Seminários Integrados fossem desenvolvidos projetos escolares interdisciplinares que integrassem conteúdos das quatro áreas do conhecimento em uma perspectiva interdisciplinar.

$\mathrm{Na}$ escola estudada, as mudanças ocasionadas por essa reforma curricular desafiaram professores e professoras, tendo em vista que esses sujeitos comumente têm sua formação e suas práticas curriculares marcadas por uma tradição disciplinar. Uma das professoras da equipe de supervisão pedagógica esclarece que o trabalho por área de conhecimento foi um grande desafio na escola.

\footnotetext{
“Com relação, por exemplo, ao ensino distribuído nas quatro áreas do conhecimento, onde eles [os professores] tiveram que trabalhar em conjunto, eu acho assim que foi a barreira maior nesse primeiro momento" ${ }^{4}$. (Entrevista com supervisora pedagógica Luciana ${ }^{5}$ ).
}

\footnotetext{
${ }^{4}$ Os dados de pesquisa obtidos por meio das entrevistas e questionários serão apresentados no formato de citação para que fiquem em destaque em relação ao texto.
} 
Ao relatar esse desafio inicial de trabalhar coletivamente por área do conhecimento, a supervisora pedagógica Luciana - Pedagoga que usualmente atuava na equipe pedagógica dos anos iniciais do ensino fundamental antes de integrar a equipe do ensino médio - avalia que os professores e professoras do ensino médio, em geral, são muito resistentes ao trabalho coletivo, pois têm sua formação voltada ao estudo e ao trabalho individual e especializado. A formação desses profissionais foi, portanto, um dos aspectos limitadores da integração curricular, repercutindo diretamente nas práticas curriculares de modo que configuram uma cultura pedagógica e docente muito diferente do que a política do Ensino Médio Politécnico promulga.

A formação inicial de professores e professoras é um campo educacional marcado por um profundo processo de especialização e fragmentação do conhecimento, que tem se intensificado historicamente, implicando na formação de profissionais despreparados para atuar com princípios pedagógicos que envolvem o trabalho coletivo, de integração de áreas do conhecimento, de ensino baseado nas relações de totalidade entre parte-todo e teoria-prática, bem como de realização de projetos interdisciplinares, tais como os princípios definidores da política do Ensino Médio Politécnico. Sobre essas questões, destacamos as palavras de Santomé (1998).

Uma situação que, a meu ver, funciona como um obstáculo às propostas de interdisciplinaridade é a grande fragmentação das Universidades [...] em especialidades. Cada especialidade trata de possuir uma faculdade exclusiva. Deste modo, cada vez mais as áreas do conhecimento ficam mais isoladas, criando-se um caldo de cultura favorável ao aparecimento de mais subespecialidades dentro de cada disciplina que integra cada área do conhecimento. [...] Essa compartimentalização [...] explica muitas das críticas às pessoas que atualmente se formam. Pessoas que estudaram apenas matérias diretamente relacionadas com a especialidade escolhida e que, portanto, saem com limitações e, às vezes, com uma sensação de auto-suficiência que as impede de abrir-se para o diálogo e para o trabalho em equipe. (SANTOMÉ, 1998, p. 81-82).

Esse descompasso - entre a formação docente e a proposta pedagógica de projetos interdisciplinares e, de modo geral, de integração curricular - coloca profundos desafios para as escolas. Considerando a declaração de Santomé, em relação aos desafios da fragmentação do conhecimento e da especialização da formação docente, destacamos a abertura para o diálogo e o trabalho em equipe como elementos fundamentais no enfrentamento de algumas dessas

${ }^{5}$ Os nomes dos/as participantes da pesquisa são fictícios para que sejam preservadas suas identidades, conforme firmado em termo de consentimento informado. 
dificuldades. Nesse sentido, os relatos dos professores e professoras que atuam na escola estudada trazem diversos fatores que dificultaram especialmente a realização do trabalho coletivo, como a falta de tempo, ausência de reuniões pedagógicas, excesso de trabalho e, muitas vezes, ausência de disposição e perspectiva de coletividade por parte dos mesmos. Os relatos de quatro professoras da escola mostram como esses fatores constituem obstáculos para a integração curricular.

“As dificuldades também apareceram, como o fator tempo para as áreas se reunirem e realizarem seus planejamentos. Ainda falta avançar, reorganizar os planos de estudos para se tornarem mais integrados”. (Questionário, professora Renata).

"Fizemos poucos trabalhos integrados, por várias razões, principalmente por desvalorização do trabalho pedagógico e pelo excesso de trabalho". (Questionário, professora Priscila).

“Com relação à integração das áreas, em poucos momentos e com poucos conteúdos foi possível fazer isso. Nós professores, na sua maioria, não nos predispomos a trabalhar de forma integrada e nossos horários também não colaboram”. (Questionário, professora Camila).

"Eu acho que se a gente tivesse reuniões na escola, que se fizesse realmente um trabalho interdisciplinar sério, o aluno teria aprendido mais. $\mathrm{O}$ que tá faltando é o trabalho colaborativo. Numa escola, se não existe o trabalho colaborativo, é complicado". (Entrevista com professora Denise, responsável por turmas de Seminários Integrados).

Tomando os relatos dessas professoras em suas relações, evidencia-se um complexo de fatores que se inter-relacionam, sustentando uma espécie de estrutura através da qual os professores e professoras mantêm-se condicionados/as a um conjunto de práticas cotidianas, que, em geral, consolidam os desafios no campo da educação escolar. Neste caso, considerando os relatos acima, a falta de tempo para o trabalho coletivo, que se traduz na ausência de reuniões pedagógicas, sustenta uma cultura institucional de trabalho individual. A individualização do trabalho, como vimos, é uma herança da especialização no campo da formação de professores (SANTOMÉ, 1998). Além disso, o trabalho individual reforça a fragmentação dos conhecimentos e, por conseguinte, a disciplinarização curricular. A tradição cultural e institucional de um currículo disciplinar relacionase estreitamente com o processo de racionalização desse campo que consolidou modelos curriculares fragmentados (SILVA, 2000). A racionalização do currículo desencadeou a intensificação, proletarização e desqualificação do trabalho docente (APPLE, 1995). Essa 
intensificação do trabalho dos professores e professoras, por sua vez, ocasiona a falta de tempo na vida profissional desses sujeitos, dificultando o trabalho coletivo.

Para compreender como esses fatores, trazidos nos relatos das professoras, relacionam-se de modo a tornarem-se uma espécie de estrutura na qual é muito difícil se movimentar e muito difícil de transpor ou romper, é importante aqui operar com o conceito de hegemonia. Apple argumenta que "a hegemonia atua para 'saturar' a nossa consciência, de maneira que o mundo educacional, econômico e social que vemos e com o qual interagimos [...] se torna o mundo tout court, o único mundo" (APPLE, 2006, p. 39). Nesse sentido, a hegemonia consiste no processo de "naturalização" dos nossos modos de pensar e agir, tornando muito difícil a articulação entre novas propostas educacionais e maneiras de interpretá-las no bojo de nossas representações comuns da realidade. Mobilizando esse conceito, portanto, pode-se dizer que a hegemonia atua na sustentação dessa estrutura, observada na escola, através de um conjunto de práticas que parecem confirmar-se reciprocamente, constituindo assim um senso de realidade além da qual é muito difícil movimentarse (APPLE, 2006; GANDIN, 2010).

É importante salientar, contudo, que nas instituições escolares existem também tendências contraditórias, resistências e conflitos em relação às forças de reprodução ideológica (APPLE, 2006). Isso significa que "a escola é um espaço em que se podem criar novas dinâmicas, em que há sujeitos concretos mediando a produção da hegemonia, que é sempre um processo e nunca um dado" (GANDIN, 2010, p. 23). A cultura institucional da escola estudada mostra claramente, através dos dados de pesquisa, esse conjunto de práticas e de relações hegemônicas sendo tensionadas pela proposta da integração curricular. $\mathrm{O}$ relato abaixo reitera essa constatação.

\footnotetext{
"Sempre foi e continua sendo muito difícil esse trabalho integrado. É muito segmentado. [...] Porque pra planejar um trabalho por área, todos os professores têm que se reunir e fazer um planejamento e continuar se encontrando, reavaliar isso, e todo o ano. E isso tem sido muito difícil, principalmente, na maioria das vezes, pela falta de tempo. Os professores não dispõem desse tempo pra isso [reuniões para o trabalho coletivo]". (Entrevista com supervisora pedagógica Maria).
}

Além dessas dificuldades relacionadas à formação docente e ao trabalho coletivo, os Seminários Integrados foram incorporados na organização curricular do Ensino Médio Politécnico de forma segmentada. A proposta de criação dos Seminários Integrados previa que esses espaços fossem integrais na sua dimensão espaço-temporal, compondo inicialmente $25 \%$ da carga horária do tempo escolar, sendo progressivamente aumentada para compor $75 \%$ no terceiro ano do curso. 
Contudo, a carga horária desse componente curricular foi distribuída na grade curricular contabilizada como hora-aula de 45 minutos e, portanto, passou a ser definida do mesmo modo como as demais disciplinas que compõem o currículo escolar, dificultando a realização de um trabalho substancial e continuado. Os relatos abaixo corroboram essa conclusão.

\footnotetext{
"O Seminário Integrado se tornou uma disciplina que o professor planeja e trabalha alguns projetos sem a colaboração das outras disciplinas e professores”. (Questionário, professora Larissa).

"[O Seminário Integrado] sempre foi considerado uma disciplina independente. [...] Durante todo o tempo que trabalhei, sempre trabalhei sozinha. Sempre trabalhei independente e sozinha". (Entrevista com professora Laura, responsável por turmas de Seminários Integrados).
}

Tendo em vista a definição operacional dos Seminários Integrados como uma disciplina, e com base nos dados de pesquisa, mostrou-se comum entre os professores e professoras (tanto responsáveis por turmas de Seminários Integrados quanto aqueles que já atuaram nesses espaços em anos anteriores) a queixa legítima de que é bastante difícil realizar um trabalho substancial com os alunos e alunas em curtos espaços de tempo entrecortados. Nestes casos, há perdas consideráveis de tempo a cada início de aula, para que esses/as estudantes sejam despertados/as para as atividades, sendo necessário constantemente que o/a professor/a dê um passo atrás no trabalho já realizado para que haja novamente o entendimento por parte dos alunos e alunas sobre a atividade que está sendo desenvolvida nos Seminários Integrados. Essa dificuldade mostrou-se repetidamente durante as observações das atividades desenvolvidas nesse componente curricular, em que eram gastos em média de 5 a 10 minutos do período de cada aula nas tarefas de conter a agitação dos alunos e alunas, retomar etapas anteriores e instigar o foco desses/as estudantes nas atividades. Nota-se, portanto, que essa disciplinarização dos Seminários Integrados ocasionou a fragmentação do trabalho pedagógico reforçando os desafios de seu desenvolvimento.

É preciso salientar, no entanto, que essa é uma dificuldade que não se restringe aos Seminários Integrados, mas uma problemática comum entre todas as disciplinas escolares. Indo ao encontro dos dados apresentados e reafirmando a problemática decorrente da estrutura curricular disciplinar, Santomé (1998) faz um alerta que se revela bastante atual, que pode também ser tomado a exemplo dos casos de reprovação que assinalam altos índices recorrentes no cenário educacional brasileiro. 
Com enorme frequência, ocorrem dificuldades de aprendizagem provenientes de uma constante mudança de atenção de uma matéria para outra. Não nos esqueçamos que nas instituições escolares onde se trabalha com base em disciplinas independentes, os módulos horários costumam dedicar blocos de 45 ou 50 minutos a cada uma delas. E existe outro fator que também é chave na hora de explicar casos de fracasso escolar: é impossível compreender bem os nexos entre os conteúdos de tais disciplinas e, assim, é preciso fazer um esforço enorme para memorizar tanto volume de informação. As demais capacidades intelectuais mal são estimuladas. (SANTOMÉ, 1998, p. 111, grifos nossos).

Mesmo reconhecendo as proporções que essa problemática alcança, consideramos prudente, tendo em vista o foco deste estudo, determo-nos particularmente sobre os desafios que a fragmentação dos tempos escolares ocasionou ao desenvolvimento dos Seminários Integrados. Sendo assim, destacamos a disciplinarização desse componente curricular como um dos principais desafios para a concretização da integração curricular no âmbito desse contexto particular, ainda que as análises aqui apresentadas possam servir para pensar outros contextos escolares.

\section{LIMITES DA INTEGRAÇÃO CURRICULAR PELO PROCESSO DE DISCIPLINARIZAÇÃO DOS SEMINÁRIOS INTEGRADOS}

Para aprofundamento dessa discussão, retomamos algumas considerações teóricas, trazidos de Bernstein (1996), que contribuem para problematizar as implicações que a compreensão dos Seminários Integrados como disciplina escolar tem sobre as possibilidades de integração curricular na perspectiva da interdisciplinaridade. Vimos que Domingos et al. (1986) explicam que Bernstein concebe a estrutura curricular disciplinar sustentada em demarcações muito rígidas entre cada uma das disciplinas. Essas demarcações de fronteiras disciplinares sinalizam o lugar que cada disciplina ocupa no currículo escolar pelas forças de classificação e de enquadramento que as constituem. Em relação a esses conceitos, é importante lembrar que a classificação é determinada pelos conteúdos e demais elementos curriculares transmitidos em uma relação pedagógica. O modo dessa transmissão, por sua vez, determina o enquadramento de uma disciplina na estrutura curricular (BERNSTEIN, 1996).

O que esses conceitos dizem sobre os Seminários Integrados é que esse componente curricular não possui demarcações rigorosas que o possam caracterizar como uma disciplina. As forças de classificação e de enquadramentos, no caso desse componente curricular, são fracas ou quase inexistentes. Sendo assim, tampouco se pode dizer que os Seminários Integrados possuem 
fronteiras, na medida em que não existem diretrizes e referenciais curriculares claros e sólidos para definição dos conteúdos a serem trabalhados no âmbito desse componente curricular.

Considerando que as sólidas fronteiras disciplinares mostraram-se um obstáculo para a concretização da integração curricular no âmbito dos Seminários Integrados, podemos considerar que os conceitos de classificação e de enquadramento, teorizados por Bernstein (1996), dizem muito mais sobre a solidez das fronteiras das disciplinas, tradicionalmente isoladas e dispostas de modo fragmentado na estrutura curricular, do que propriamente sobre os Seminários Integrados. Ainda que esse componente curricular não seja caracterizado por fronteiras bem definidas que consolidem sua classificação na estrutura curricular, é notório que as demais disciplinas possuem suas fronteiras muito bem definidas, tão sólidas que sua classificação no interior do currículo escolar tem força pujante nas disputas por mais espaço (e tempo) na estrutura curricular estratificada. Com base nisso, embora os Seminários Integrados fossem espaços pretensamente abertos ao atravessamento e às inter-relações das disciplinas que compõem o currículo escolar, a solidez das fronteiras destas últimas (também por força das "fronteiras" que isolam as práticas de professores e professoras em um trabalho individual, como vimos anteriormente) tornou-se uma barreira nesse processo.

Como exemplo dessa barreira das disciplinas em detrimento da abertura dos Seminários Integrados ao trabalho mais colaborativo, destacamos a dificuldade que a professora Laura ${ }^{6}$ encontrou no diálogo com os colegas para desenvolver um trabalho em uma das suas turmas de Seminários Integrados. A professora relata que no primeiro trimestre de 2016 ela desenvolveu com essa turma um talk show, baseando-se em personagens históricos. Cada estudante escolheu uma personagem, pesquisou sobre a biografia da mesma, caracterizou-se conforme a mesma e elaborou um roteiro que seria encenado no dia da apresentação do talk show com base na biografia pesquisada. Para desenvolver esse trabalho, a professora Laura solicitou a colaboração de professores e professoras de sete disciplinas, a saber, Geografia, História, Filosofia, Sociologia, Ética e Cidadania, Português e Literatura.

\footnotetext{
${ }^{6}$ Professora Laura tem formação inicial em História e possui Pós-Graduação na área de História. No momento desta pesquisa, o tempo de atuação da professora no magistério era de 13 anos, dos quais 05 foram na escola estudada. Professora de História em turmas dos anos finais do ensino fundamental, atuou como professora de Seminários Integrados por 02 anos em turmas de $1^{\circ}$ ano do ensino médio.
} 
"No primeiro trimestre, foi feito esse trabalho, foi desenvolvido esse talk show [...] inclusive, entreguei esse trabalho valendo para sete disciplinas e os alunos sabem disso. [...] foi entregue a biografia com as questões [...] eu entreguei pra todos os meus colegas, todos os titulares das disciplinas. [...] Português poderia corrigir, poderia ter utilizado como forma de avaliação corrigindo a redação; a História da forma que pudesse interpretar; a Geografia, localização, onde morou, onde viveu, podia ter avaliado dessa forma; Ética e Cidadania, a influência dessa pessoa na sociedade; Filosofia e Sociologia também, com certeza se foi uma pessoa que teve influência dentro da sociedade, então teve seu pensamento, deixou um legado. [...] inclusive, os alunos tiveram gastos, despesas com isso, fazendo as cópias das biografias pra ser entregue. Isso foi entregue então, esses resumos, essas biografias, para cada titular das suas disciplinas, mas eu não tive retorno, eu não tive retorno dos colegas". (Entrevista com professora Laura, responsável por turmas de Seminários Integrados).

Esse esforço preliminar de integração curricular, ainda que elementar, por meio do trabalho colaborativo, teve como barreira maior nesse momento a isenção dos demais professores e professoras diante da possibilidade do diálogo, mantendo-se exilados/as pelas forças de classificação e enquadramento de suas disciplinas (BERNSTEIN, 1996). Cabe aqui salientar que "Um corpo docente que pesquise e trabalhe em equipe é algo consubstancial a este modelo de currículo [integrado]" (SANTOMÉ, 1998, p. 29), modelo esse proposto no contexto do Ensino Médio Politécnico e sinalizado em demais diretrizes e referenciais curriculares nacionais.

Outro importante fator que se mostrou desafiador à integração curricular por meio dos Seminários Integrados, refere-se à ausência de referenciais curriculares por parte da política do Ensino Médio Politécnico para o desenvolvimento desse componente curricular, que pudessem conduzir e sustentar as práticas curriculares e pedagógicas nesses espaços. Essas lacunas no que diz respeito a proposições operacionais desafiaram professores e professoras tanto na realização dos seus planejamentos quanto nas suas práticas pedagógicas, o que provocou muito mais resistências, confusões, frustrações e incertezas nesse contexto. Essas dificuldades marcadas pelas lacunas na proposta podem ser constatadas no que expressam as professoras envolvidas nessa experiência de integração curricular. 
"A gente não tem uma proposta consistente, estreita, que diga "tal área vai resgatar isso"”. (Entrevista com professora Denise, responsável por turmas de Seminários Integrados).

"Faltou uma base muito grande [...] Eu me sinto assim um pouco frustrada nesse sentido, de não ter tido uma base melhor pra isso [Seminário Integrado], um apoio maior que faltava, um referencial teórico [...] Faltou um norte!”. (Entrevista com professora Laura, responsável por turmas de Seminários Integrados).

“A integração ficou só no papel, pois não realizamos o trabalho dentro da proposta. Um dos motivos foi a falta de conhecimento da proposta, pois foi algo imposto pela SEDUC-RS e pouco estudado". (Questionário, professora Samanta).

“Até hoje, a gente tem dúvida de muita coisa, nosso grupo. Tanto que chega final de ano, a gente tem que se reunir para pensar o que a gente fez; o que deu certo e o que não deu certo, para continuar". (Entrevista com supervisora pedagógica Vera).

Nota-se que os limites da integração curricular que se sobressaem nesse contexto não podem ser assumidos pela perspectiva da responsabilização daqueles que nele atuam. Entendemos a necessidade de um reposicionamento nesse contexto. Uma releitura desses limites (APPLE, 1989), bem como uma perspectiva relacional (APPLE, 2006) sobre esse campo curricular mostram-nos a importância de considerar que

A elaboração de políticas a favor da interdisciplinaridade obriga a prestar atenção em uma série de condições; de maneira especial, exige mudanças nas estruturas institucionais, novas relações entre os especialistas [profissionais da educação] baseadas na colaboração [...] e uma ligação cada vez mais íntima entre as instituições universitárias de pesquisa e ensino com o resto das esferas da sociedade. (SANTOMÉ, 1998, p. 83).

Para além dos desafios da prática, Santomé (1998) também argumenta que existe uma complexidade no conceito de interdisciplinaridade que o torna pouco claro. "Algo que pode ser facilmente observado nos trabalhos e discursos sobre a interdisciplinaridade é a pouca clareza deste conceito. Não se trata de um termo cujo significado goza de total consenso" (SANTOMÉ, 1998, p. 45). A interdisciplinaridade, portanto, é um desafio que transcende o campo da educação. Nesse caso, é importante reconhecer que existem barreiras epistemológicas e culturais que precisam ser repensadas e superadas nas diversas esferas que se relacionam com a educação. 


\title{
CONCLUSÕES
}

À guiza de conclusão, destacamos um registro de uma das professoras da escola sobre o desmantelamento da proposta de integração curricular.

\begin{abstract}
"O porquê de não ter dado certo? Falta de planejamento conjunto com as disciplinas; a escola não priorizou reuniões para discutir ou para que os professores apresentassem suas propostas; a carga horária excessiva [de trabalho] dos professores; a política de desvalorização dos professores; entre outros fatores, contribuíram para o fim dessa prática".
\end{abstract}

(Questionário, professora Larissa).

Esse registro encerra reiterando os fatores que se colocaram como entraves a esse processo e, mais do que isso, marcando seu fim no contexto dessa escola, tendo em vista as fragilidades tanto na organização curricular como nas tentativas de integração promovidas por esta escola frente às diversas dificuldades documentadas neste trabalho. Além desses desafios, o desmantelamento da proposta de integração curricular também, e sobretudo, ocorreu pela ausência de regulamentação e de assistência pedagógica e financeira por parte da equipe da SEDUC-RS responsável pela gestão no período de 2015-2018. Salientamos ainda que as marcas de desvalorização profissional docente, de isolamento dos profissionais nas fronteiras engessadas de suas disciplinas e de um trabalho solitário no âmbito dos Seminários Integrados - assumidos nesse contexto sob o rótulo da disciplinarização - reforçaram os limites da integração curricular a partir de princípios que requerem dos professores e professoras uma perspectiva de diálogo, inter-relações e totalidade no desenvolvimento dos seus trabalhos.

Sendo assim, em relação às possibilidades e aos limites da prática interdisciplinar na perspectiva da integração curricular, é importante reiterar que as análises realizadas neste estudo, mobilizadas pelo conceito de hegemonia, evidenciam a necessidade de superar barreiras epistemológicas e culturais que provêm de esferas macrossociais e políticas para que se possa, desse modo, avançar no âmbito das práticas locais (escolares, curriculares e pedagógicas), no micro contexto de atuação dos professores e professoras.

A partir dos desafios documentados neste estudo, compreendemos que, no contexto da escola estudada, sobressaíram-se as práticas curriculares cristalizadas por uma hegemonia atuante na manutenção de toda uma tradição que caracteriza esta cultura escolar. Embora a proposta do Ensino Médio Politécnico contrarie e tensione essa hegemonia em suas concepções, ela não conseguiu, no contexto estudado, criar as condições para a concretização de um currículo integrado. 
Nesse sentido, os campos da formação de professores, do currículo e das políticas educacionais (não apenas de concepções gerais, mas de criação de alternativas concretas) mostram-se espaços que precisam ser repensados e reestruturados fundamentalmente se é que se busca uma numa perspectiva interdisciplinar de integração curricular.

\section{REFERÊNCIAS}

APPLE, Michael W. Ideologia e Currículo. Trad. Vinicius Figueira. Porto Alegre: Artmed, 2006. APPLE, Michael W. Política Cultural e Educação. Trad. Maria José do Amaral Ferreira. São Paulo: Cortez, 2000.

APPLE, Michael W. Educação e Poder. Trad. Maria Cristina Monteiro. Porto Alegre: Artmed, 1989.

APPLE, Michael W. Trabalho Docente e Textos: economia política das relações de classe e de gênero em educação. Trad. Tomaz Tadeu da Silva, Tina Amado e Vera Maria Moreira. Porto Alegre: Artes Médicas, 1995.

BERNSTEIN, Basil. A estruturação do discurso pedagógico: Classe, Códigos e Controle. Trad. Tomaz Tadeu da Silva e Luís Fernando Gonçalves Pereira. Petrópolis: Vozes, 1996.

DOMINGOS, Ana Maria; BARRADAS, Helena; RAINHA, Helena; NEVES, Isabel Pestana. A Teoria de Bernstein em Sociologia da Educação. Lisboa: Fundação Calouste Gulbenkian, 1986.

GANDIN, Luís Armando. Michael Apple: a educação sob a ótica da análise relacional. In: Revista Educação. Pedagogia Contemporânea. Número 4 - Currículo e Política Educacional. São Paulo: Editora Segmento, 2010.

RIO GRANDE DO SUL. Secretaria de Estado da Educação. Proposta pedagógica para o ensino médio politécnico e educação profissional integrada ao ensino médio 2011-2014. Porto Alegre: SEDUC/RS. 2011. Disponível em: 〈http://www.educacao.rs.gov.br/dados/ens_med_proposta.pdf〉. Acesso em: <28.jun.2012>.

SACRISTÁN, J. Gimeno. O Currículo: uma reflexão sobre a prática. Trad. Ernani F. da F. Rosa. Porto Alegre: Artmed, 2000.

SANTOMÉ, Jurjo Torres. Globalização e interdisciplinaridade: o currículo integrado. Porto Alegre: Artes Médicas, 1998.

SILVA, Teresinha Maria Neli. A construção do currículo na sala de aula: o professor como pesquisador. São Paulo: EPU, 1990.

SILVA, Tomaz Tadeu da. Teorias do Currículo: uma introdução crítica. Coleção Currículo, Políticas e Práticas. Porto/Portugal: Porto Editora, 2000.

SILVA, Tomaz Tadeu da. O que produz e o que reproduz em educação: ensaios de Sociologia da Educação. Porto Alegre: Artes Médicas, 1992. 


\section{DESAFIOS DA INTEGRAÇÃO CURRICULAR: A PRÁTICA INTERDISCIPLINAR NOS ESPAÇOS DOS SEMINÁRIOS INTEGRADOS}

\section{RESUMO}

Este artigo tem como objetivo apresentar uma discussão sobre os desafios da integração curricular no contexto do Ensino Médio Politécnico, tendo como foco a prática interdisciplinar e os espaços dos Seminários Integrados. O referencial teórico-metodológico estruturante deste trabalho congrega as Teorias Educacionais Críticas e a Sociologia da Educação, buscando compreender os desafios no campo do currículo a partir das experiências de professores e professoras no contexto de uma política de reforma curricular. Os caminhos metodológicos deste estudo foram orientados por observações, entrevistas e questionários com professores e professoras de uma escola da rede pública estadual do Rio Grande do Sul. Os Seminários Integrados eram o espaço no qual deveria ter havido a integração das áreas do conhecimento em uma perspectiva interdisciplinar. No entanto, a pesquisa evidencia diversos obstáculos para a concretização da integração curricular, entre os quais destacamos a formação docente, as lacunas na própria proposta curricular e a disciplinarização dos Seminários Integrados.

Palavras-chave: Currículo. Integração curricular. Interdisciplinaridade.

\section{CHALLENGES TO CURRICULAR INTEGRATION: THE INTERDISCIPLINARY PRACTICE IN THE CONTEXT OF THE INTEGRATED SEMINARS}

\section{ABSTRACT}

This article aims to present a discussion about the challenges of curriculum integration in the context of Polytechnic High School, focusing on interdisciplinary practice and the spaces of Integrated Seminars. The theoretical-methodological framework of this research brings together Critical Educational Theories and Sociology of Education, seeking to understand the challenges in the curriculum field derived from the experiences of teachers in the context of a curriculum reform policy. The methodological paths of this study were guided by observations, interviews and questionnaires with teachers of a public state school of Rio Grande do Sul. Integrated Seminars were the space in which knowledge areas should have been integrated into an interdisciplinary perspective. However, this research shows many obstacles to the achievement of curriculum integration, among which we highlight teacher education, the gaps in the curricular proposal and the disciplinarization of Integrated Seminars.

Keywords: Curriculum. Curricular Integration. Interdisciplinar practices. 


\section{DESAFÍOS PARA LA INTEGRACIÓN CURRICULAR: LA PRÁCTICA \\ INTERDISCIPLINARIA EN EL CONTEXTO DE LOS SEMINARIOS INTEGRADOS}

\section{RESUMEN}

Este artículo tiene como objetivo presentar una discusión sobre los desafíos de la integración del currículo en el contexto de la Escuela Secundaria Politécnica, enfocándose en la práctica interdisciplinaria y los espacios de Seminarios Integrados. El marco teórico-metodológico estructurante de este trabajo reúne las Teorías educativas críticas y la Sociología de la educación, buscando comprender los desafíos en el campo del currículo a partir de las experiencias de los docentes en el contexto de una política de reforma curricular. La metodología de este estudio fue guiada por observaciones, entrevistas y cuestionarios con profesores de una escuela del estado de Rio Grande do Sul. Los seminarios integrados fueron el espacio en el que las áreas de conocimiento deberían haberse integrado en una perspectiva interdisciplinaria. Sin embargo, la investigación destaca varios obstáculos para el logro de la integración del plan de estudios, entre los que destacamos la formación del profesorado, los problemas en la propuesta del plan de estudiosy la disciplinarización de los seminarios integrados.

Palabras clave: Currículo. Integración curricular. Interdisciplinariedad.

Submetido em Agosto de 2019

Aprovado em Dezembro de 2019 